\title{
Brain MRI lesions and atrophy are associated with employment status in patients with multiple sclerosis
}

\author{
Shahamat Tauhid ${ }^{1} \cdot$ Renxin Chu $^{1} \cdot$ Rahul Sasane $^{2} \cdot$ Bonnie I. Glanz $^{1}$ • \\ Mohit Neema $^{1}$ - Jennifer R. Miller ${ }^{1}$ - Gloria Kim ${ }^{1} \cdot$ James E. Signorovitch $^{3}$. \\ Brian C. Healy ${ }^{1} \cdot$ Tanuja Chitnis $^{1} \cdot$ Howard L. Weiner $^{1} \cdot$ Rohit Bakshi $^{1,4,5}$
}

Received: 24 May 2015/Revised: 7 July 2015/Accepted: 8 July 2015/Published online: 24 July 2015

(c) The Author(s) 2015. This article is published with open access at Springerlink.com

\begin{abstract}
Multiple sclerosis (MS) commonly affects occupational function. We investigated the link between brain MRI and employment status. Patients with MS $(n=100)$ completed a Work Productivity and Activity Impairment (WPAI) (general health version) survey measuring employment status, absenteeism, presenteeism, and overall work and daily activity impairment. Patients "working for pay" were considered employed; "temporarily not working but looking for work," "not working or looking for work due to age," and "not working or looking for work due to disability" were considered not employed. Brain MRI T1 hypointense (T1LV) and T2 hyperintense (T2LV) lesion volumes were quantified. To assess lesional destructive capability, we calculated each subject's ratio of T1LV to T2LV (T1/T2). Normalized brain parenchymal volume (BPV) assessed brain atrophy. The mean (SD) age was 45.5 (9.7) years; disease duration was 12.1 (8.1) years; $75 \%$ were women, $76 \%$ were relapsing-remitting, and $76 \%$ were employed. T1LV, T1/ T2, Expanded Disability Status Scale (EDSS) scores, and activity impairment were lower and BPV was higher in the
\end{abstract}

Rohit Bakshi

rbakshi@post.harvard.edu

1 Laboratory for Neuroimaging Research, Department of Neurology, Partners MS Center, Harvard Medical School, Brigham and Women's Hospital, Boston, MA, USA

2 Novartis Pharmaceuticals, East Hanover NJ, USA

3 Analysis Group, Inc., Boston, MA, USA

4 Laboratory for Neuroimaging Research, Department of Radiology, Partners MS Center, Harvard Medical School, Brigham and Women's Hospital, Boston, MA, USA

5 Laboratory for Neuroimaging Research, One Brookline Place, Brookline, MA 02445, USA employed vs. not employed group (Wilcoxon tests, $p<0.05)$. Age, disease duration, MS clinical subtype, and T2LV did not differ between groups $(p>0.05)$. In multivariable logistic regression modeling, adjusting for age, sex, and disease duration, higher T1LV predicted a lower chance of employment $(p<0.05)$. Pearson correlations showed that EDSS was associated with activity impairment $(p<0.05)$. Disease duration, age, and MRI measures were not correlated with activity impairment or other WPAI outcomes $(p>0.05)$. We report a link between brain atrophy and lesions, particularly lesions with destructive potential, to MS employment status.

Keywords Employment $\cdot$ Productivity $\cdot$ Multiple sclerosis · MRI · Brain atrophy · Brain lesions · Disability

\section{Introduction}

The compromised ability to perform occupational function and unemployment is commonly seen in multiple sclerosis (MS) [1-8]. Impaired work performance is related to a variety of disease manifestations including physical disability, cognitive impairment, psychological factors, pain, and fatigue [1-4, 6-13]. Furthermore, in addition to the financial impact of occupational limitations, such impairment may significantly lower quality of life $[2,14]$.

MRI of the brain is a valuable tool for the diagnosis and longitudinal monitoring of patients with MS [15]. MRI imaging can depict a variety of effects of the disease process, such as the development of $\mathrm{T} 1$ hypointense lesions, T2 hyperintense lesions, and atrophy [15, 16]. A growing body of evidence has linked MRI-defined disease severity to key clinical manifestations such as physical disability, mood disturbances, and cognitive impairment [15-24]. 
However, to date, the relationship between MRI and occupational function has not been evaluated.

In a recent cross-sectional study, we administered a work productivity scale to patients with MS and identified a role for disability, depression, fatigue, and anxiety in impairment of occupational functions [2]. In the present study, we extended our previous observations in this cohort by examining the available MRI scans to assess the link between brain lesions/atrophy and employment status/ productivity.

\section{Methods}

\section{Subjects and clinical evaluation}

As part of the Comprehensive Longitudinal Investigation of Multiple Sclerosis at Brigham and Women's Hospital (CLIMB) study [25], we previously reported employmentrelated data on 377 patients with a clinically isolated demyelinating syndrome (CIS) or relapsing-remitting MS (RRMS), based on the administration of the Work Productivity and Activity Impairment (WPAI) questionnaire (general health version) [2].

The WPAI survey, administered during a scheduled clinical visit in the CLIMB study, measured employment status, absenteeism, presenteeism (impairment during work), overall work impairment, and daily activity impairment. Patients who reported "working for pay" were classified as employed ( $n=76)$. While those "temporarily not working but looking for work," "not working or looking for work due to age," and "not working or looking for work due to disability" were considered not employed $(n=16)$. Patients who were not classified as employed or not employed ( $n=8$ ) because they were working in home ( $n=4)$, volunteering $(n=1)$, or in school $(n=3)$ were excluded from the analysis comparing the employed vs. not employed groups.

During the same clinical visit, patients also underwent a neurologic examination by an MS neurologist to rate physical disability using the Expanded Disability Status Scale (EDSS) [26]. To qualify for this MRI-based substudy, patients were required to have undergone brain imaging on the assigned CLIMB study MRI scanner using a consistent acquisition protocol that included a 3D highresolution scan and was performed within 90 days of the clinical visit. One hundred patients were identified, the clinical and demographic characteristics of whom are shown in Table 1.

All subjects gave informed consent. This study was approved by the Partners Health Care ethics committee and was performed in accordance with the ethical standards of the 1964 Declaration of Helsinki and its later amendments.

\section{MRI acquisition}

Brain MRI was performed in all subjects on a $1.5 \mathrm{~T}$ scanner (GE Signa, Milwaukee, WI). Scan acquisitions covered the whole brain and included an axial T1-weighted spin-echo (TR/TE: 725/20 ms) and dual-echo T2-weighted (TR/TE2/ TE1: $3000 / 80 / 30 \mathrm{~ms}$ ) series (voxel size $0.94 \times 0.94$ $\times 3 \mathrm{~mm}$ ) and a sagittal 3D MP-RAGE sequence (TR/TE: $8.6 / 3.8 \mathrm{~ms}$ ) with a voxel size of $0.94 \times 0.94 \times 1.2 \mathrm{~mm}$. T1-weighted spin-echo imaging was repeated $5 \mathrm{~min}$ after $0.1 \mathrm{~mol} / \mathrm{kg}$ intravenous gadolinium (Gd).

\section{MRI analysis: lesions}

Brain T1 hypointense (T1LV) and T2 hyperintense lesion volume (T2LV) were expert-quantified with an edge-finding tool using Jim software (v.5, Xinapse Systems Ltd, West Bergholt, UK, http://www.xinapse.com/). T2 hyperintense lesions were defined as those showing hyperintensity on both the proton density and late echo T2-weighted images. T1 hypointense lesions ("black holes") were required to show at least partial hyperintensity on the dualecho images, but no gadolinium-enhancement (to reduce the likelihood of including transient lesions) [15]. To assess a patient's lesional destructive capability, we calculated the ratio of $\mathrm{T} 1 \mathrm{LV}$ to $\mathrm{T} 2 \mathrm{LV}$ (T1/T2) for each subject, based on our previous work showing the value of this metric [27-29].

\section{MRI analysis: atrophy}

To assess whole brain atrophy, we measured normalized brain parenchymal volume (BPV) from the 3D MP-RAGE images using the fully automated segmentation-based algorithm, Structural Image Evaluation using Normalization of Atrophy (SIENAX) [30]. Our method has been previously detailed [31]. Briefly, the automated process involved extraction of the brain and CSF volume from the whole-head input data, followed by affine-registration to a standardized space. The volumetric scaling factor was then obtained for normalization by head size. Tissue-type segmentation with partial volume estimation was then conducted to calculate the total volume of brain tissue vs. CSF. Optimization experiments led to our use of the default brain extraction threshold of 0.5 to maintain adequate segmentation in each image set.

\section{Statistical analysis}

Baseline descriptive statistics were summarized, and baseline age, disease duration, EDSS, brain volume measures, and activity impairment were compared between employed vs. not employed patients using the Wilcoxon 
Table 1 Multiple sclerosis patient characteristics

\begin{tabular}{|c|c|}
\hline Age, years: Mean \pm SD (range) & $\begin{array}{l}45.5 \pm 9.7 \\
(19.9-64.8)\end{array}$ \\
\hline Female, $n(\%)$ & $75(75.0)$ \\
\hline \multicolumn{2}{|l|}{ Race, $n(\%)$} \\
\hline Black or African American & $4(4.0)$ \\
\hline South Asian & $1(1.0)$ \\
\hline White & $94(94.0)$ \\
\hline Unknown & $1(1.0)$ \\
\hline \multicolumn{2}{|l|}{ Employment status, $n(\%)$} \\
\hline Working for pay & $76(76.0)$ \\
\hline Working in home & $4(4.0)$ \\
\hline Volunteering & $1(1.0)$ \\
\hline In school & $3(3.0)$ \\
\hline $\begin{array}{l}\text { Temporarily not working but looking for } \\
\text { work }\end{array}$ & $3(3.0)$ \\
\hline $\begin{array}{l}\text { Not working or looking for work because of } \\
\text { age }\end{array}$ & $2(2.0)$ \\
\hline $\begin{array}{l}\text { Not working or looking for work because of } \\
\text { disability }\end{array}$ & $11(11.0)$ \\
\hline $\begin{array}{l}\text { MS disease duration, years: Mean } \pm \text { SD } \\
\text { (range) }\end{array}$ & $\begin{array}{c}12.1 \pm 8.1 \\
(1.6-36.6)\end{array}$ \\
\hline \multicolumn{2}{|l|}{ MS category, $n(\%)$} \\
\hline Clinically isolated syndrome & $6(6.0)$ \\
\hline Relapsing-remitting & $76(76.0)$ \\
\hline Secondary progressive & $12(12.0)$ \\
\hline Primary progressive & $6(6.0)$ \\
\hline $\begin{array}{l}\text { Brain parenchymal volume, } \mathrm{mL} \text { : Mean } \pm \mathrm{SD} \\
\text { (range) }\end{array}$ & $\begin{array}{l}1429.7 \pm 70.7 \\
\quad(1216.3-1574.7)\end{array}$ \\
\hline $\begin{array}{l}\text { T1 hypointense lesion volume, } \mathrm{mL} \text { : } \\
\text { Mean } \pm \mathrm{SD} \text { (range) }\end{array}$ & $1.3 \pm 2.1(0.0-9.5)$ \\
\hline $\begin{array}{l}\mathrm{T} 2 \text { hyperintense lesion volume, } \mathrm{mL} \text { : } \\
\text { Mean } \pm \mathrm{SD} \text { (range) }\end{array}$ & $4.9 \pm 6.7(0.1-28.3)$ \\
\hline $\begin{array}{l}\mathrm{T} 1 / \mathrm{T} 2 \text { lesion volume ratio: Mean } \pm \mathrm{SD} \\
\text { (range) }\end{array}$ & $0.3 \pm 0.2(0.0-0.7)$ \\
\hline EDSS: Mean \pm SD (range) & $2.2 \pm 1.9(0.0-7.5)$ \\
\hline \multicolumn{2}{|l|}{ WPAI:GH, mean $\pm \mathrm{SD}, \%$} \\
\hline Activity impairment $(n=99)$ & $21.0 \pm 26.5$ \\
\hline Overall work impairment $(n=74)$ & $18.3 \pm 25.6$ \\
\hline $\begin{array}{l}\text { Absenteeism (i.e., percent work time } \\
\text { missed, } n=74 \text { ) }\end{array}$ & $6.7 \pm 19.7$ \\
\hline $\begin{array}{l}\text { Presenteeism (i.e., days at work but limited } \\
\text { in performing job tasks due to health, } \\
n=72 \text { ) }\end{array}$ & $13.5 \pm 20.1$ \\
\hline
\end{tabular}

$n=100$ unless otherwise indicated

EDSS expanded disability status scale, WPAI:GH work productivity and activity impairment-general health

rank-sum test. Correlations between patient characteristics and WPAI General Health scores were assessed using Pearson's correlation coefficient for all variables except for EDSS, for which the associations were measured using Spearman's rho. Logistic regression models were used to explore whether employment status was associated with brain volume and lesion volume. Age, sex, and disease duration were included as covariates in the logistic regression models. All data analyses were performed using SAS release 9.3 (SAS Institute, Inc., Cary, NC).

\section{Results}

Patient demographic, clinical, and MRI characteristics are shown in Table 1. Among the 100 patients analyzed in the correlation analysis, $74 \%$ had absenteeism and $72 \%$ had presenteeism data. A total of 12 patients had an absenteeism score $>0$, while 33 patients had a presenteeism score $>0$. The main results are shown in Tables 2 and 3 and Figs. 1, 2, 3, 4. Seven patients had Gd-enhanced lesions; however, due to power considerations and study design, we did not formally compare patients for the presence or absence of Gd-enhancing lesions in relation to employment in this study. As shown in Table 2 and Figs. 1, 2, and 4, T1LV, T1/T2, Expanded Disability Status Scale (EDSS) scores, and activity impairment were lower and BPV was higher in the employed vs. not employed group (Wilcoxon tests, $p<0.05$; Wilcoxon rank-sum tests, $p<0.05)$. Age, disease duration, T2LV, and clinical subtype of MS were not significantly different between groups $(p>0.05)$ (Tables 2 and 3, Fig. 3). Spearman's correlation coefficient showed that EDSS was associated with activity impairment $(p<0.05)$ (Table 4$)$. However, disease duration, age, and MRI variables were not correlated with activity impairment, absenteeism, presenteeism, or overall work impairment (all $p>0.05$ ).

\section{Regression Modeling}

To further explore the strength of the relationship between MRI and MS employment status, we developed three logistic regression models (each adjusting for age, sex, and disease duration): (1) T1LV vs. employment status, (2) T1/ T2 vs. employment status, and (3) BPV vs. employment status. In the first multivariable logistic regression model, we found a statistically significant reduction $(p=0.047)$ in the odds of being employed vs. unemployed by $22.4 \%$ for each $1 \mathrm{~mL}$ increase in T1LV. We did not observe a significant association between T1/T2 $(p=0.144)$ or BPV $(p=0.191)$ and employment status in the second and third multivariable models.

\section{Discussion}

The major finding in this study is the increased disease severity as shown by MRI-defined cerebral lesions and atrophy in MS patients who are not employed vs. those 
Table 2 Clinical/MRI multiple sclerosis disease variables in employed vs. not employed patients

Table 3 Clinical subtype of multiple sclerosis by employment status

\begin{tabular}{lcc}
\hline & $\begin{array}{l}\text { Mean difference } \\
\text { employed }(n=76) \\
\text { vs. not employed }(n=16)\end{array}$ & $\begin{array}{l}\text { Wilcoxon } \\
\text { rank-sum } \\
\text { test } p \text { value }^{\mathrm{b}}\end{array}$ \\
\hline Patient characteristics $^{\mathrm{a}}$ & & \\
Age $^{\mathrm{c}}$ & -4.429 & 0.090 \\
Disease duration $_{\text {Baseline EDSS }}$ & -0.008 & 0.857 \\
Brain volume measures $^{\mathrm{a}}$ & -2.030 & $<0.001$ \\
BPV & & \\
T1LV & 3.645 & 0.036 \\
T2LV & -1.288 & 0.014 \\
T1/T2 LV ratio & -1.739 & 0.107 \\
Activity Impairment & -0.093 & 0.012 \\
\hline
\end{tabular}

EDSS Expanded Disability Status Scale score, $B P V$ brain parenchymal volume, $L V$ lesion volume

a This analysis was conducted among patients who reported any of the following: "working for pay," "temporarily not working but looking for work," not working or looking for work due to age," and "not working or looking for work due to disability." Patients who reported "working for pay" were considered employed. BPV, T1, and T2 lesion volumes are measured in $\mathrm{mL}$

${ }^{\mathrm{b}} p$ values were estimated using a non-parametric Wilcoxon rank-sum test for two independent samples

${ }^{c}$ When stratified by employment status, the mean age among employed patients was 44.9 (SD 8.6) with a range of 27.1-62.6 years and the mean age among not employed patients was 49.3 (SD 10.5) with a range of 29.8-64.8 years. Note that the regression modeling testing the relationships between MRI and employment status were adjusted for age, sex, and disease duration (see "Results" Section)

\begin{tabular}{lll}
\hline & Employed, $n(\%)$ & Not employed, $n(\%)$ \\
\hline Clinically isolated syndrome & $5(6.6)$ & $1(6.3)$ \\
Relapsing-remitting & $60(78.9)$ & $10(62.5)$ \\
Secondary progressive & $6(7.9)$ & $4(25.0)$ \\
Primary progressive & $5(6.6)$ & $1(6.3)$ \\
\hline
\end{tabular}

There was no significant difference between employed $(n=76)$ and not employed $(n=16)$ groups in terms of the distribution of multiple sclerosis clinical subtype $(p>0.05)$

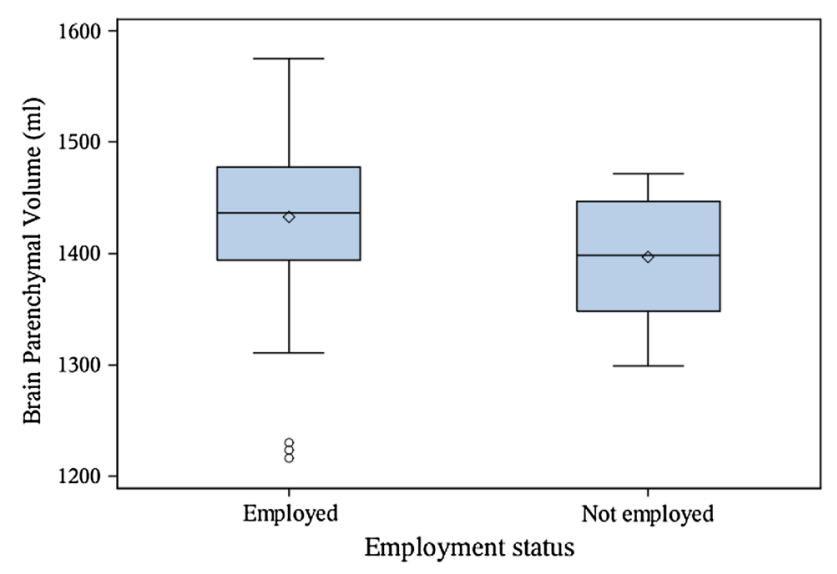

Fig. 1 Brain atrophy is associated with MS employment status. Boxplot with mean (diamond), median, quartiles, $95 \%$ interval whiskers and outliers. Wilcoxon rank-sum test: $p$ value $=0.036$

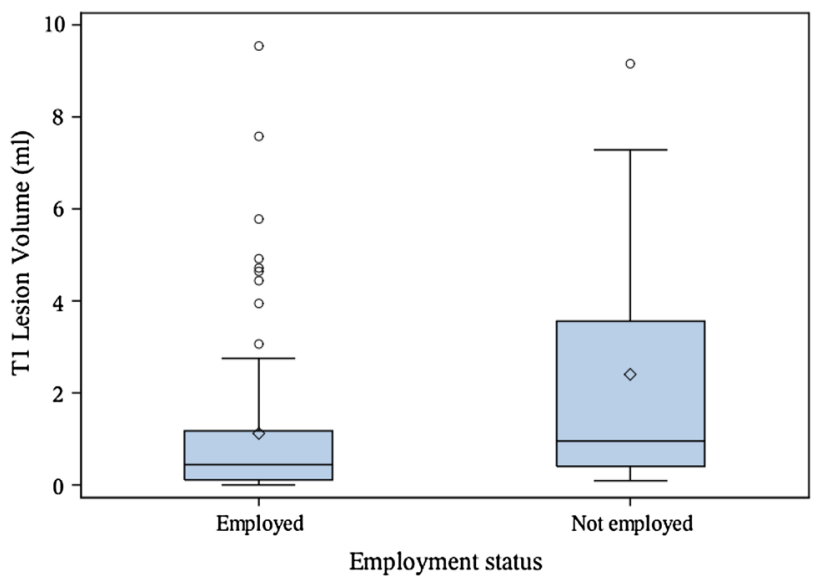

Fig. 2 Brain T1 hypointense lesion volume is associated with MS employment status. Boxplot with mean (diamond), median, quartiles, $95 \%$ interval whiskers and outliers. Wilcoxon rank-sum test: $p$ value $=0.014$ 


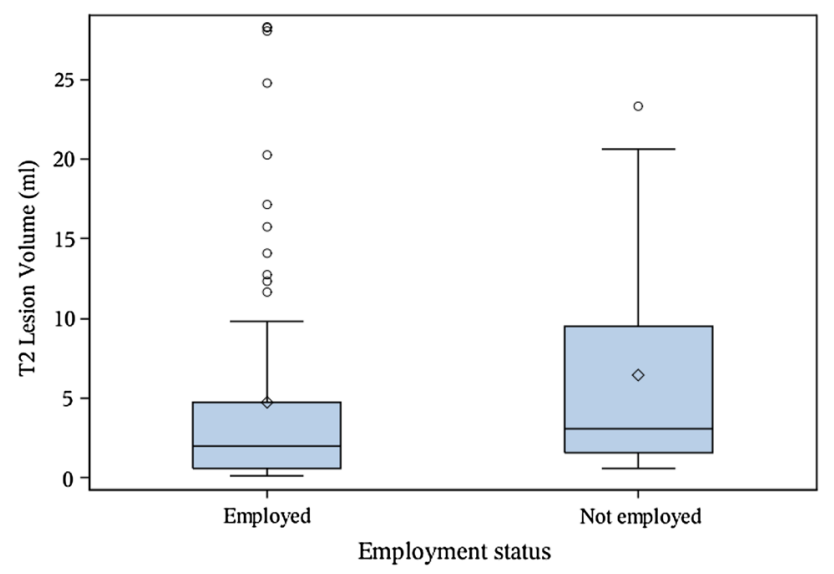

Fig. 3 Brain T2 hyperintense lesion volume is not associated with MS employment status. Boxplot with mean (diamond), median, quartiles, $95 \%$ interval whiskers and outliers. Wilcoxon rank-sum test: $p$ value $=0.107$

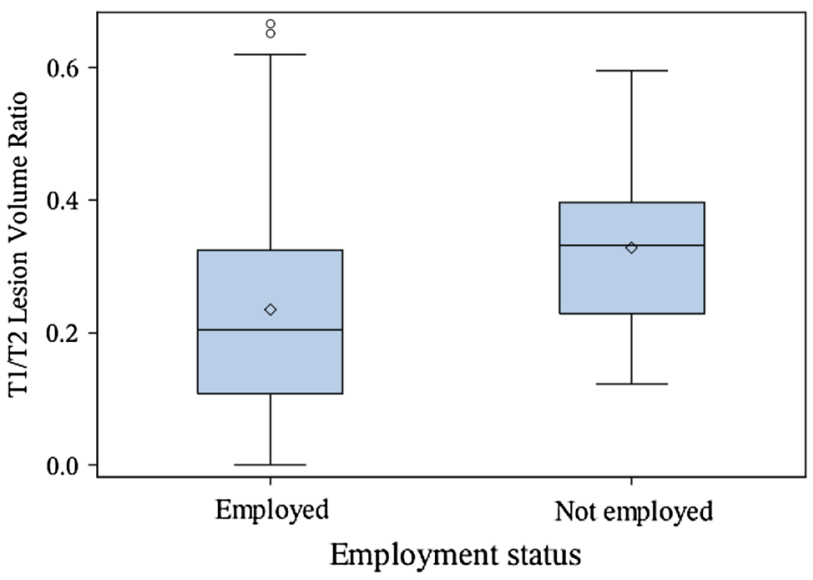

Fig. 4 Brain T1/T2 lesion volume ratio is associated with MS employment status. Boxplot with mean (diamond), median, quartiles, $95 \%$ interval whiskers and outliers. Wilcoxon rank-sum test: $p$ value $=0.012$

who are employed. Among lesion measures, the destructive potential as assessed by the overall $\mathrm{T} 1$ hypointense burden and the proportion of $\mathrm{T} 2$ hyperintense lesions showing $\mathrm{T} 1$ hypointensity were most strongly related to the employment status. In addition, normalized whole brain volume was higher in employed vs. not employed patients, suggesting that brain atrophy was also a factor linked to not employed status.

These findings are perhaps not surprising given that a range of neurological and neuropsychological dysfunction in MS, such as physical disability, cognitive impairment, and mood disturbances, have been linked to both impaired work performance [1-4, 6-13] and brain structural damage as defined on MRI scans by lesions and atrophy [22, 32]. Among MRI lesion measures, T1 hypointense lesions have

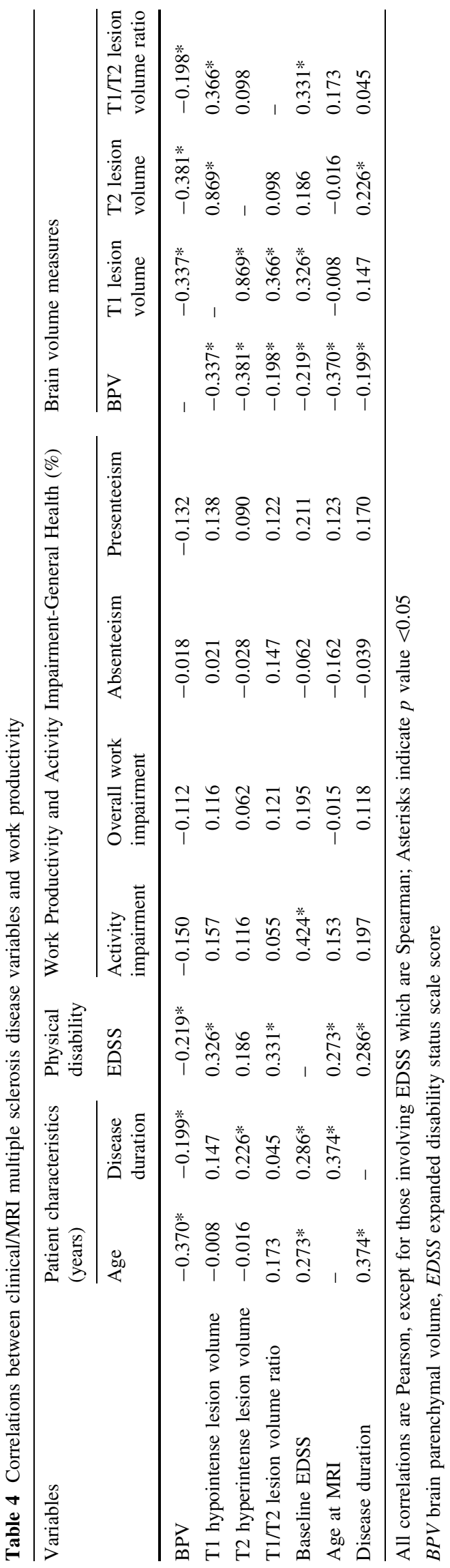


shown both more specificity for destructive irreversible damage [33] and better correlations with mental and physical impairment $[24,34]$ than $\mathrm{T} 2$ hyperintense lesions. These previous studies are in line with our results that $\mathrm{T} 1$ hypointense lesions are also more important for employment status than $\mathrm{T} 2$ hyperintense lesions.

The second major finding was that none of the MRI variables were associated with activity impairment in the whole cohort or any work productivity measures in the employed patients, including overall work impairment, absenteeism, or presenteeism. These aspects of impairment were not common in our sample. Thus, the study may have been underpowered to detect such associations due to the restricted range of activity impairment. Secondly, the latter three measures of impairment are only relevant to employed patients and thus may not have provided sufficient sensitivity. Furthermore, these self-reported measures may not have been reliable. We did not assess any objective measures of productivity while working. Finally, the presence of cognitive reserve [35], which was not assessed in our study, may have provided adaptive ability for patients to maintain function, despite the accumulation of disease-related structural brain changes.

A third finding was the strong relationship between physical disability, assessed by EDSS score, and both employment status and activity impairment. Such a relationship has been long known in MS. However, it was striking in our data that EDSS score showed a closer link than the MRI variables to employment and activity impairment. This important role for disability was seen from two perspectives. First, the differences between employed and not employed groups were robust for EDSS $(p<0.001)$, while less robust for MRI brain atrophy and T1 hypointense lesion variables $(p<0.05)$. Second, EDSS score, but not MRI variables, showed a significant correlation with activity impairment. One possible explanation for this divergence is the heavy contribution of spinal cord involvement to the EDSS score [26], whereas only brain MRI measures were applied in this study. It is likely that spinal cord involvement, a major contributor to limb and ambulatory disability [29, 36-41], is a key contributor to vocational skills, and is poorly reflected in the level of MRI-defined brain lesions or atrophy in patients with MS [36].

Our cohort was dominated by mildly affected patients with relapsing forms of MS. Given that only $18 \%$ of our patients had progressive forms of MS, further studies are required to assess the link between brain MRI findings and employment in advanced forms of the disease. Sample size should also be taken into account as the not employed group comprised 16 patients. We are now planning to study larger cohorts. Additional work is necessary to establish whether the relationships between MRI and employment are independent from the effects of cognitive impairment and fatigue. Because of sample size and the restricted range of employment impairment, there may have been limited power to detect the full extent of MRI relationships. It would be of interest for future studies to test whether other aspects of MRI-defined involvement in MS, such as spinal cord [36-41], cortical [42, 43], and diffuse cerebral damage [44-46], are related to productivity and whether MRI findings predict longitudinal change of employment status. Destructive effects of lesions may be particularly prominent using ultra-high-field strength MRI [47]. In summary, our study demonstrates a clear relationship between brain MRI and employment status in MS.

\section{Compliance with the ethical standards}

Conflicts of interest This study was funded by Novartis Pharmaceuticals. It is based on data from the Comprehensive Longitudinal Investigation of Multiple Sclerosis at Brigham and Women's Hospital (CLIMB) study, funded in part by Merck Serono. Rahul Sasane is an employee of Novartis Pharmaceuticals. Bonnie Glanz and Brian Healy received research support from Merck Serono. Tanuja Chitnis received consulting fees from Biogen, Merck Serono, and Alexion and research support from Merck Serono and Novartis. Howard Weiner received personal compensation from Biogen, Novartis, EMD Serono, Teva, GSK, Nasvax, Xenoport, and Genzyme and research support from Merck Serono. Rohit Bakshi received consulting fees from AbbVie, Alkermes, Biogen, Novartis, and Questcor and research support from Biogen, Merck Serono, Novartis, Genzyme, and Teva. The other authors state that there is no conflict of interest. This work was presented in preliminary form at the 2014 joint meeting of the Americas and European Committees on Treatment and Research in Multiple Sclerosis (ACTRIMS/ECTRIMS), Boston, MA, USA.

Open Access This article is distributed under the terms of the Creative Commons Attribution 4.0 International License (http://crea tivecommons.org/licenses/by/4.0/), which permits unrestricted use, distribution, and reproduction in any medium, provided you give appropriate credit to the original author(s) and the source, provide a link to the Creative Commons license, and indicate if changes were made.

\section{References}

1. Bøe Lunde HM, Telstad W, Grytten N, Kyte L, Aarseth J, Myhr KM et al (2014) Employment among patients with multiple sclerosis-a population study. PLoS One 9(7):e103317

2. Glanz BI, Dégano IR, Rintell DJ, Chitnis T, Weiner HL, Healy BC (2012) Work productivity in relapsing multiple sclerosis: associations with disability, depression, fatigue, anxiety, cognition, and health-related quality of life. Value Health 15(8): $1029-1035$

3. Honarmand K, Akbar N, Kou N, Feinstein A (2011) Predicting employment status in multiple sclerosis patients: the utility of the MS functional composite. J Neurol 258(2):244-249

4. Julian LJ, Vella L, Vollmer T, Hadjimichael O, Mohr DC (2008) Employment in multiple sclerosis: exiting and re-entering the work force. J Neurol 255(9):1356-1360

5. Messmer Uccelli M, Specchia C, Battaglia MA, Miller DM (2009) Factors that influence the employment status of people 
with multiple sclerosis: a multi-national study. J Neurol 256(12):1989-1996

6. Moore P, Harding KE, Clarkson H, Pickersgill TP, Wardle M, Robertson NP (2013) Demographic and clinical factors associated with changes in employment in multiple sclerosis. Mult Scler 19(12):1647-1654

7. Morse CL, Schultheis MT, McKeever JD, Leist T (2013) Multitasking in multiple sclerosis: can it inform vocational functioning? Arch Phys Med Rehabil 94(12):2509-2514

8. Schiavolin S, Leonardi M, Giovannetti AM, Antozzi C, Brambilla L, Confalonieri P et al (2013) Factors related to difficulties with employment in patients with multiple sclerosis: a review of 2002-2011 literature. Int J Rehabil Res 36(2):105-111

9. Krause I, Kern S, Horntrich A, Ziemssen T (2013) Employment status in multiple sclerosis: impact of disease-specific and nondisease-specific factors. Mult Scler 19(13):1792-1799

10. Morrow SA, Drake A, Zivadinov R, Munschauer F, WeinstockGuttman B, Benedict RH (2010) Predicting loss of employment over three years in multiple sclerosis: clinically meaningful cognitive decline. Clin Neuropsychol 24(7):1131-1145

11. Smith MM, Arnett PA (2005) Factors related to employment status changes in individuals with multiple sclerosis. Mult Scler 11(5):602-609

12. Strober LB, Christodoulou C, Benedict RH, Westervelt HJ, Melville P, Scherl WF et al (2012) Unemployment in multiple sclerosis: the contribution of personality and disease. Mult Scler 18(5):647-653

13. Strober L, Chiaravalloti N, Moore N, DeLuca J (2014) Unemployment in multiple sclerosis (MS): utility of the MS functional composite and cognitive testing. Mult Scler 20(1):112-115

14. Miller A, Dishon S (2006) Health-related quality of life in multiple sclerosis: the impact of disability, gender and employment status. Qual Life Res 15(2):259-271

15. Filippi M, Preziosa P, Rocca MA (2014) Magnetic resonance outcome measures in multiple sclerosis trials: time to rethink? Curr Opin Neurol 27(3):290-299

16. Bermel RA, Bakshi R (2006) The measurement and clinical relevance of brain atrophy in multiple sclerosis. Lancet Neurol 5(2): $158-170$

17. Shiee N, Bazin PL, Zackowski KM, Farrell SK, Harrison DM, Newsome SD et al (2012) Revisiting brain atrophy and its relationship to disability in multiple sclerosis. PLoS ONE 7(5):e37049

18. Magon S, Chakravarty MM, Amann M, Weier K, Naegelin Y, Andelova $\mathrm{M}$ et al (2014) Label-fusion-segmentation and deformation-based shape analysis of deep gray matter in multiple sclerosis: the impact of thalamic subnuclei on disability. Hum Brain Mapp 35(8):4193-4203

19. Poonawalla AH, Datta S, Juneja V, Nelson F, Wolinsky JS, Cutter G et al (2010) Composite MRI scores improve correlation with EDSS in multiple sclerosis. Mult Scler 16(9):1117-1125

20. Popescu V, Agosta F, Hulst HE, Sluimer IC, Knol DL, Sormani MP et al (2013) Brain atrophy and lesion load predict long term disability in multiple sclerosis. J Neurol Neurosurg Psychiat 84(10):1082-1091

21. Uher $\mathrm{T}$, Blahova-Dusankova J, Horakova D, Bergsland $\mathrm{N}$, Tyblova M, Benedict RH et al (2014) Longitudinal MRI and neuropsychological assessment of patients with clinically isolated syndrome. J Neurol 261(9):1735-1744

22. Benedict RHB, Carone DA, Bakshi R (2004) Correlating brain atrophy with cognitive dysfunction, mood disturbances, and personality disorder in multiple sclerosis. J Neuroimaging 14(Suppl):36S-45S

23. Gold SM, O'Connor MF, Gill R, Kern KC, Shi Y, Henry RG et al (2014) Detection of altered hippocampal morphology in multiple sclerosis-associated depression using automated surface mesh modeling. Hum Brain Mapp 35(1):30-37

24. Bakshi R, Czarnecki D, Shaikh ZA, Priore RL, Janardhan V, Kaliszky Z et al (2000) Brain MRI lesions and atrophy are related to depression in multiple sclerosis. NeuroReport 11(6):1153-1158

25. Gauthier SA, Glanz BI, Mandel M, Weiner HL (2006) A model for the comprehensive investigation of a chronic autoimmune disease: the multiple sclerosis CLIMB study. Autoimmun Rev 5(8):532-536

26. Kurtzke JF (1983) Rating neurologic impairment in multiple sclerosis: an expanded disability status scale (EDSS). Neurology 33:1444-1452

27. Bakshi R, Neema M, Healy BC, Liptak Z, Betensky RA, Buckle GJ et al (2008) Predicting clinical progression in multiple sclerosis with the Magnetic Resonance Disease Severity Scale. Arch Neurol 65(11):1449-1453

28. Moodie J, Healy BC, Buckle GJ, Gauthier SA, Glanz BI, Arora A et al (2012) Magnetic Resonance Disease Severity Scale (MRDSS) for patients with multiple sclerosis: a longitudinal study. J Neurol Sci 315(1-2):49-54

29. Bakshi R, Neema M, Tauhid S, Healy BC, Glanz BI, Kim G et al (2014) An expanded composite scale of MRI-defined disease severity in multiple sclerosis: MRDSS2. NeuroReport 25(14):1156-1161

30. Smith SM, Rao A, De Stefano N, Jenkinson M, Schott JM, Matthews PM et al (2007) Longitudinal and cross-sectional analysis of atrophy in Alzheimer's disease: cross-validation of BSI, SIENA and SIENAX. Neuroimage 36(4):1200-1206

31. Chu R, Tauhid S, Glanz BI, Healy BC, Kim G, Oommen VV et al (2015) Whole brain volume measured from 1.5T vs. 3T MRI in healthy subjects and patients with multiple sclerosis. J Neuroimaging. doi:10.1111/jon.12271

32. Zivadinov R, Leist TP (2005) Clinical-magnetic resonance imaging correlations in multiple sclerosis. J Neuroimaging 15(4 Suppl):10S-21S

33. Truyen $\mathrm{L}$, van Waesberghe JH, van Walderveen MA, van Oosten BW, Polman CH, Hommes OR et al (1996) Accumulation of hypointense lesions ("black holes") on T1 spin-echo MRI correlates with disease progression in multiple sclerosis. Neurology 47(6):1469-1476

34. van Walderveen MA, Kamphorst W, Scheltens P, van Waesberghe JH, Ravid R, Valk J et al (1998) Histopathologic correlate of hypointense lesions on T1-weighted spin-echo MRI in multiple sclerosis. Neurology 50(5):1282-1288

35. Sumowski JF, Leavitt VM (2013) Cognitive reserve in multiple sclerosis. Mult Scler 19(9):1122-1127

36. Cohen AB, Neema M, Arora A, Dell'Oglio E, Benedict RH, Tauhid S et al (2012) The relationships among MRI-defined spinal cord involvement, brain involvement, and disability in multiple sclerosis. J Neuroimaging 22(2):122-128

37. Lin X, Tench CR, Evangelou N, Jaspan T, Constantinescu CS (2004) Measurement of spinal cord atrophy in multiple sclerosis. J Neuroimaging 14(3 Suppl):20S-26S

38. Schlaeger R, Papinutto N, Panara V, Bevan C, Lobach IV, Bucci $M$ et al (2014) Spinal cord gray matter atrophy correlates with multiple sclerosis disability. Ann Neurol 76(4):568-580

39. Furby J, Hayton T, Altmann D, Brenner R, Chataway J, Smith KJ et al (2010) A longitudinal study of MRI-detected atrophy in secondary progressive multiple sclerosis. J Neurol 257(9):1508-1516

40. Klawiter EC, Schmidt RE, Trinkaus K, Liang HF, Budde MD, Naismith RT et al (2011) Radial diffusivity predicts demyelination in ex vivo multiple sclerosis spinal cords. Neuroimage 55(4):1454-1460 
41. Ciccarelli O, Altmann DR, McLean MA, Wheeler-Kingshott CA, Wimpey K, Miller DH et al (2010) Spinal cord repair in MS: does mitochondrial metabolism play a role? Neurology 74(9):721-727

42. Nielsen AS, Kinkel RP, Tinelli E, Benner T, Cohen-Adad J, Mainero C (2012) Focal cortical lesion detection in multiple sclerosis: 3 Tesla DIR versus 7 Tesla FLASH-T2. J Magn Reson Imaging 35(3):537-542

43. Nelson F, Poonawalla A, Datta S, Wolinsky J, Narayana P (2014) Is 3D MPRAGE better than the combination DIR/PSIR for cortical lesion detection at 3T MRI? Mult Scler Relat Disord $3(2): 253-257$

44. Wattjes MP, Harzheim M, Lutterbey GG, Bogdanow M, Schild $\mathrm{HH}$, Träber $\mathrm{F}$ (2008) High field $\mathrm{MR}$ imaging and 1H-MR spectroscopy in clinically isolated syndromes suggestive of multiple sclerosis: correlation between metabolic alterations and diagnostic MR imaging criteria. J Neurol 255(1):56-63

45. Inglese M, Oesingmann N, Zaaraoui W, Ranjeva JP, Fleysher L (2013) Sodium imaging as a marker of tissue injury in patients with multiple sclerosis. Mult Scler Relat Disord 2(4):263-269

46. Filippi M, Rocca MA, Barkhof F, Brück W, Chen JT, Comi G et al (2012) Association between pathological and MRI findings in multiple sclerosis. Lancet Neurol 11(4):349-360

47. Sinnecker T, Mittelstaedt P, Dörr J, Pfueller CF, Harms L, Niendorf T et al (2012) Multiple sclerosis lesions and irreversible brain tissue damage: a comparative ultrahigh-field strength magnetic resonance imaging study. Arch Neurol 69(6):739-745 